\title{
Evaluation of transrectal examination of cervical diameter by palpation in dairy cows
}

\author{
C. Leutert, V. Suthar, and W. Heuwieser ${ }^{1}$ \\ Clinic of Animal Reproduction, Faculty of Veterinary Medicine, Freie Universität Berlin, Königsweg 65, 14163 Berlin, Germany
}

\begin{abstract}
The objective of the study was to evaluate the reliability of a manual assessment of cervical diameter through palpation. In an in vivo trial, 64 HolsteinFriesian cows between 2 and $5 \mathrm{~d}$ in milk (DIM) and between 21 and 27 DIM were examined by transrectal palpation by 3 investigators. For calculation of sensitivity and specificity, ultrasound-generated measurements were used as reference standard; a cervix $>7.5 \mathrm{~cm}$ was categorized as large. The Pearson coefficient of correlation between the results of the 3 investigators and ultrasound-generated measurements was moderate ( $\mathrm{r}$ $=0.71,0.74$, and 0.51). The estimates generated by palpation by the 3 different investigators did not differ and were similar to measurements obtained by ultrasound. The coefficient of variation (CV) between the investigators and ultrasound was high $(20.9,18.7$, and $32.0 \%$ ). The mean difference between the investigators and the ultrasound was $0.60 \mathrm{~cm}$ (95\% confidence interval: -2.4 to 3.6 ). Sensitivity was $28.6,42.9$, and $42.9 \%$, and specificity was $100,96.2$, and $92.6 \%$ for the ability of the 3 investigators, respectively, to detect the $7.5-\mathrm{cm}$ cutoff by palpation. Overall sensitivity and specificity for all 3 investigators, considering ultrasound as the reference, were 37.5 and $96.2 \%$, respectively. In vitro, 24 wooden cylinders were used to represent cervical diameter and to examine the reliability, as well as sensitivity and specificity, of manual assessment of different diameters. The Pearson coefficient of correlation between the results of the investigators $(n=11)$ and the actual diameters of the cylinders was 0.78 . The CV between the investigators and the cylinders was $27.8 \%$. The variation in the results was greater for cylinders with a larger diameter (3.5-cm diameter: mean \pm standard deviation $=2.6 \pm 0.9 \mathrm{~cm} ; 10.5$-cm diameter: mean \pm standard deviation $=13.2 \pm 4.0 \mathrm{~cm}$ ). The estimate obtained by palpation for the $7.5-\mathrm{cm}$ cylinder was 7.4 $\pm 2.1 \mathrm{~cm}$. Sensitivity was $79.4 \%$ and specificity $92.5 \%$. After training one group of investigators, sensitivity
\end{abstract}

Received August 15, 2012.

Accepted September 30, 2012.

${ }^{1}$ Corresponding author: w.heuwieser@fu-berlin.de and specificity improved to 85.9 and $94.4 \%$, respectively. Transrectal palpation of the cervical diameter shows moderate repeatability and correlation and high variation between the investigators and the reference standards. Variability increased with larger diameters. Key words: clinical endometritis, cervical diameter, diagnosis, test characteristic

\section{INTRODUCTION}

The negative effect of uterine diseases of postpartum cows on reproductive performance is well documented through several publications (e.g., McDougall et al., 2007; Runciman et al., 2008). One important postpartum uterine disease in dairy cows is clinical endometritis $(\mathbf{C E})$. Two recent studies established a scientifically sound and clinically useful case definition of CE based on factors that are prognostic for impaired reproductive performance (LeBlanc et al., 2002a; Sheldon et al., 2006). Clinical endometritis is defined as a cervical diameter $>7.5 \mathrm{~cm}$ determined by transrectal palpation after 20 DIM or as mucopurulent or purulent vaginal discharge by vaginoscopy after 26 DIM. Cows with $\mathrm{CE}$ have significantly decreased fertility (LeBlanc et al., 2002a). Recently, it was demonstrated that the likelihood of returning to cyclicity decreased for each $1-\mathrm{cm}$ increase in cervical diameter measured by ultrasound between 15 and $21 \mathrm{~d}$ postpartum (López-Helguera et al., 2012).

The cervix is an important barrier against invasion of bacteria into the uterus (Bekana et al., 1996, 1997). Thus, cervical closure and regaining the firm structure of the cervix after parturition are important for reproductive performance (van Engelen et al., 2007). Besides purulent uterine discharge, delayed involution of the cervix is the only other predictive sign for reduced pregnancy rate, and it has been considered a simple and objective clinical finding for the diagnosis of $\mathrm{CE}$ (LeBlanc et al., 2002a).

Transrectal palpation of the uterus to assess its size lacks diagnostic accuracy, as large uteri may reflect physical damage or variations associated with breed, age, or nutrition (Dohmen et al., 2000; LeBlanc et al., 2002a; Sheldon et al., 2006). Kelton et al. (1991) al- 
ready reported evidence of inter-clinician variability in the accuracy of assessment of corpus luteum presence by transrectal palpation. Currently, data are lacking on the repeatability of assessment of cervical diameter estimated by transrectal palpation. Therefore, the overall objective of this study was to determine the reliability of a manual assessment of the cervical diameter through transrectal palpation. Specifically, we set out to (1) evaluate the sensitivity and specificity using a reference standard, (2) determine the inter-observer repeatability, and (3) study the human ability to assess cylinders of known diameters through palpation by means of an in vitro experiment.

\section{MATERIALS AND METHODS}

\section{In Vivo}

The study was conducted on 2 dairy farms in Brandenburg, Germany, between July and December 2010. The herd size was 1,200 and 180 cows in herds A and $\mathrm{B}$, respectively. The cows in herd A were housed year round in freestall facilities with cubicles, rubber mats, and slotted floors. They were grouped in pens holding approximately 100 cows depending on lactation and reproduction status. Calving pens were bedded with straw. Average milk yield was $10,050 \mathrm{~kg} / \mathrm{cow}$ per lactation with $4.3 \%$ fat and $3.1 \%$ protein. A TMR was fed, consisting of $39.7 \%$ concentrate and mineral mix, $32.9 \%$ grass silage, and $19.2 \%$ corn silage $\left(\mathrm{NE}_{\mathrm{L}}=1.65\right.$ $\mathrm{Mcal} / \mathrm{kg})$.

The cows in herd B were housed in a deep-bedded barn. A TMR was fed but composition information was not available. Average milk yield was $9,482 \mathrm{~kg} /$ cow per lactation with $4.2 \%$ fat and $3.6 \%$ protein.

Before the study, an informed consent was obtained from both herd owners. Sixty-four cows were selected by a random allocation plan generated with PASW (PASW Statistics 18.0, SPSS Inc., Munich, Germany) and enrolled in the study between July and December 2010. Three independent investigators (Inv) examined cows between 2 and 5 DIM or between 21 and 27 DIM within $10 \pm 3 \mathrm{~min}$ by transrectal palpation. The same 3 investigators were utilized throughout the study; to ensure independent results, each investigator documented his or her findings on case report forms without the other investigators present. The investigators were certified veterinarians, and their experience in transrectal palpation (i.e., >150 cows) was established by means of a questionnaire before the herd visit. To control the results obtained by palpation, the cows were also examined by ultrasound.

Four experiments were conducted. The objective of experiment 1 was to determine the intra-observer repeatability of cervical diameters determined by ultrasound conducted by the same investigator. From each cervix, 2 ultrasound images were recorded within 1 min, measured twice both vertically and horizontally using the internal caliper cow side, and stored on an internal drive. The investigation was conducted using a portable, battery-powered ultrasound device (Tringa, Esaote Pie Medical, Maastricht, the Netherlands), a linear transducer, and a probe frequency of $7.5 \mathrm{MHz}$.

Experiment 2 tested inter-observer repeatability of cervical diameters measured by ultrasound as described above. Two investigators examined the cows using transrectal ultrasound independently within $5 \pm 2 \mathrm{~min}$.

Experiment 3 compared the results of transrectal palpation with those determined by ultrasound. Three investigators (Inv 1, 2, and 3) examined cows by transrectal palpation to estimate the cervical diameter $(\mathrm{cm})$ within 1 min and documented their results. The results of transrectal palpation were compared with values obtained through ultrasound examination by another investigator, as described in experiment 1 . Sensitivity and specificity were calculated for Inv 1, 2, and 3 using the ultrasound results as reference standard.

In experiment 4 , results of transrectal palpation by 3 different investigators (Inv 1, 2, and 3) were compared. The investigators assessed cervical diameter by transrectal palpation within $1 \mathrm{~min}$.

\section{In Vitro}

An in vitro trial utilizing a reference standard was conducted to establish test characteristics of estimates of cervical diameter obtained through transrectal palpation and to study whether the ability to conduct a manual assessment could be improved by training. To create reference standards representing different cervical diameters, 24 wooden cylinders were custom-made. The cylinders were $20 \mathrm{~cm}$ long and ranged between 3.5 and $10.5 \mathrm{~cm}$ in diameter, in $0.3-\mathrm{cm}$ increments. The cylinders were placed into a drainpipe (length $=57$ $\mathrm{cm}$, inner diameter $=15 \mathrm{~cm}$ ) enclosed by a wooden box $(45 \times 25 \times 20 \mathrm{~cm})$. The investigators had to manually palpate the cylinders from above but could not access the cross section, which was hidden behind a crescentshaped board located $20 \mathrm{~cm}$ from the rear end of the pipe. The author (C. Leutert) inserted the cylinders from the front end of the pipe and the investigators were located at the other end. Camouflage was attached to the box on the investigator side, which ensured that the investigators could palpate, but not see, the wooden cylinders.

In total, 10 replicates were conducted in 10 consecutive weeks with 11 investigators (final-year veterinary students). Per replicate, each investigator had to assess 
24 cylinders. Each time, the wooden cylinders were presented to the investigators in randomized order based on a random treatment allocation plan generated before initiation of the trial by using the random number function of Excel (Microsoft Office 2003, Microsoft Deutschland GmbH, Munich, Germany). The investigators were divided into 2 groups. In group A $(\mathrm{n}=5)$, the investigators did not receive any information about the diameter of the cylinders in the first 5 replicates. In replicates 6 to 10, the author (C. Leutert) provided feedback about the diameter of the cylinder after each assessment. In group B $(\mathrm{n}=6)$, the investigators did not receive any information about the diameter of the cylinders during all 10 replicates.

\section{Statistical Methods}

The analyses were performed with Excel (Microsoft Office 2003), PASW Statistics for Windows (PASW statistics 18.0, SPSS Inc.), and Medcalc software (version 10.1.3.0, Medcalc, Mariakerke, Belgium). The assessments of the cylinder diameters were documented in Excel and transferred into PASW and Medcalc. The overall prevalence of a large cervix (defined as a diameter $>7.5 \mathrm{~cm}$; LeBlanc et al., 2002a) was calculated from the ultrasound-generated results of experiment 1. The relationships between the investigators were evaluated by Pearson coefficient of correlation. For every experiment, means and standard deviations of differences between measurements were calculated. Means of differences between investigators were tested using paired $t$-test. To compare more than 2 investigators with each other, a one-way ANOVA was conducted.

Repeatability was estimated by calculating the mean and $95 \%$ CI of the arithmetic differences between repeated measurements on the same subject, according to Bland and Altman (1986). If the differences are normally distributed, $95 \%$ of the differences will lie within a range of $1.96 \mathrm{SD}$ of the mean difference. This range will be referred to as the limits of agreement.

The variation between the investigators and the reference standards was calculated with the CV from duplicate measurements with Medcalc and was considered as good when the CV was around $10 \%$.

The sensitivity and specificity of the human ability to assess diameters by palpation were calculated using results generated by ultrasound in vivo and the diameters of the wooden cylinders in vitro as reference standards, respectively. Sensitivity was calculated as the proportion of the cervices or cylinders correctly diagnosed as $>7.5 \mathrm{~cm}$ by palpation. Specificity was calculated as the proportion of the cervices or cylinders correctly diagnosed as $\leq 7.5 \mathrm{~cm}$ by palpation.

\section{RESULTS}

\section{In Vivo}

For experiments 1, 3, and 4, 64 cows in total were examined. Two cows were excluded from analyses due to injuries in the rectum and 1 due to a cervix that was not palpable. Sixty-one cows were included in the final analyses. Nineteen cows were examined between 2 and 5 DIM (group A) and 42 cows were examined between 21 and 27 DIM (group B). In none of the cows examined between 21 and 27 DIM was a cervix $>7.5$ $\mathrm{cm}$ diagnosed, whereas in 8 cows examined between 2 and 5 DIM, the diameter of the cervix was $>7.5 \mathrm{~cm}$. This resulted in an overall prevalence of $13.1 \%$ ( $\mathrm{n}=$ 8). In experiment 2, we included 27 cows: 9 examined between 2 and 5 DIM and 18 examined between 21 and 27 DIM. Pearson coefficient of correlation of 2 ultrasound-generated measurements conducted by a single investigator (experiment 1$)$ was $0.97(P<0.001)$. The mean difference between the 2 measurements of the investigator was $0.1 \pm 0.5 \mathrm{~cm}(P=0.73)$. Pearson coefficient of correlation of ultrasound-generated measurements by 2 investigators (experiment 2) was 0.99 $(P<0.05, \mathrm{n}=27)$; the $\mathrm{CV}$ was $3.4 \%$. The mean difference between the 2 investigators was $0.01 \mathrm{~cm}(95 \% \mathrm{CI}$ : -0.48 to $0.51 \mathrm{~cm})$.

In experiment 3, estimates of cervical diameter obtained through transrectal palpation were compared with ultrasound-generated measurements. The mean differences between cervical diameters estimated by manual palpation and the ultrasound-generated reference were $0.7 \pm 1.2 \mathrm{~cm}(P<0.001), 0.5 \pm 1.2 \mathrm{~cm}(P=$ $0.004)$, and $0.5 \pm 2.1 \mathrm{~cm}(P=0.08)$ for Inv 1,2 , and 3 , respectively. The coefficients of correlation (r) between Inv 1,2 , and 3 and the ultrasound-generated reference were $0.71,0.74$, and 0.51 (all $P<0.001$ ), respectively. The CV was $20.9,18.7$, and $32.0 \%$, respectively. The mean difference between Inv 1, 2, and 3 and ultrasound was $0.60 \mathrm{~cm}$ (95\% CI: -2.4 to 3.6), indicating an underestimation of the actual size by the investigators.

In experiment 4 , we compared assessment by Inv 1 , 2 , and 3 of cervical diameter through transrectal palpation. The ANOVA did not reveal any differences $(P=$ 0.72 ) between the 3 investigators. The mean differences were $0.3 \pm 1.2 \mathrm{~cm}$ (Inv 1 vs. Inv $2 ; P=0.1$ ), $0.3 \pm$ $2.0 \mathrm{~cm}$ (Inv 1 vs. Inv $3 ; P=0.33$ ), and $0.2 \pm 2.2 \mathrm{~cm}$ (Inv 2 vs. Inv $3 ; P=0.1$ ), respectively. The coefficient of correlation $(\mathrm{r})$ between the investigators were 0.79 , 0.52 , and 0.49 (all $P<0.001$ ), respectively. The CV were 19.9, 33.3, and $33.8 \%$ for Inv 1 and 2 , Inv 1 and 3 , and Inv 2 and 3, respectively.

The overall sensitivity and specificity for all 3 investigators, considering ultrasound as the reference, 
were 37.5 and $96.2 \%$, respectively. The sensitivity was $28.6,42.9$, and $42.9 \%$ and the specificity $100,96.2$, and $92.6 \%$ for Inv 1, 2, and 3, respectively, using the ultrasound-measured diameter as reference $(\mathrm{n}=61)$ and a cervical diameter $>7.5 \mathrm{~cm}$ as threshold (LeBlanc et al., 2002a). All investigators diagnosed cows with a cervical diameter $>6.0 \pm 0.2 \mathrm{~cm}$ as falling into the large cervix category $(>7.5 \mathrm{~cm})$; that is, false-positive results.

\section{In Vitro}

The Pearson coefficient of correlation increased from replicates 1 to 5 (i.e., no feedback) to replicates 6 to 10 (feedback of actual diameter) in group A (0.73 and 0.93 , both $P<0.05 ; \mathrm{n}=5)$, whereas it did not change in group B (0.74 and 0.73 , both $P<0.05 ; \mathrm{n}=6)$ from the first 5 to the second 5 replicates.

The mean difference between manual assessment of the diameter and actual size for investigators of groups $\mathrm{A}(\mathrm{n}=5)$ and $\mathrm{B}(\mathrm{n}=6)$ was $0.38 \pm 2.1 \mathrm{~cm}(P<0.001)$ and $0.37 \pm 2.4 \mathrm{~cm}(P<0.001)$, respectively, considering the first 5 replicates. In replicates 6 to 10, the mean difference was $0.11 \pm 1.8 \mathrm{~cm}(P<0.001)$ and $0.43 \pm$ $1.9 \mathrm{~cm}(P<0.001)$ for groups $\mathrm{A}$ and $\mathrm{B}$, respectively.

The repeatability between the manually assessed measurements and the cylinders improved after training (Figures 1 and 2). Furthermore, the variation of the manually obtained estimates of the cylinders in group A improved (replicates 1 to $5: \mathrm{CV}=27.6 \%, \mathrm{SD}=1.52$; replicates 6 to $10: \mathrm{CV}=8.4 \%, \mathrm{SD}=0.59)$ compared with group B (replicates 1 to $5: \mathrm{CV}=28.4 \%, \mathrm{SD}=$ 1.89; replicates 6 to $10: \mathrm{CV}=27.3 \%, \mathrm{SD}=1.91$ ) after training. The repeated assessments of the 24 wooden cylinders once a week revealed that the variation of the estimates was greater in cylinders with a larger diameter (diameter of $3.5 \mathrm{~cm}$ : mean $\pm \mathrm{SD}=2.6 \pm 0.9$ $\mathrm{cm}$; diameter of $7.5 \mathrm{~cm}$ : mean $\pm \mathrm{SD}=7.4 \pm 2.1 \mathrm{~cm}$; diameter of $10.5 \mathrm{~cm}$ : mean $\pm \mathrm{SD}=13.2 \pm 4.0 \mathrm{~cm}$; Figures 1 and 2).

Overall sensitivity and specificity (11 investigators, 2,640 assessments) were 79.4 and $92.5 \%$, respectively. In the first and last 5 replicates of group A $(\mathrm{n}=5)$, sensitivity and specificity were 73.2 and $89.4 \%$ ( $\mathrm{n}=$ $600)$ and 85.9 and $94.4 \%(\mathrm{n}=600)$, respectively. Group $\mathrm{B}(\mathrm{n}=6)$ showed sensitivity and specificity of 72.8 and $90.3 \%$ for the first 5 replicates, and 71.5 and $89.8 \%$ for the last 5 replicates.

\section{DISCUSSION}

The objective of the present study was to evaluate accuracy and repeatability of manual assessment of cervical diameter through transrectal palpation in dairy cows. A diameter of $>7.5 \mathrm{~cm}$ has been demonstrated to be a reliable predictor for reproductive performance (LeBlanc et al., 2002a). Although the most common diagnostic technique for endometritis in clinical practice is rectal palpation (LeBlanc et al., 2002a), only limited science-based information is available on the accuracy and repeatability of diagnostic approaches that depend on a manual assessment of diameters of anatomical structures. Based on the current literature, we speculated that findings generated by transrectal examination are influenced by inter-observer variability (Kelton et al., 1991).

LeBlanc et al. (2002a) established a scientifically sound and clinically useful case definition of CE based on cows being examined after 20 DIM. Interestingly, only $38.9 \%$ of the cows classified as clinically endometritic had a cervical diameter $>7.5 \mathrm{~cm}$. Regardless, a cervical diameter $>7.5 \mathrm{~cm}$ was the only independent predictor of reduced pregnancy rate besides the presence of purulent discharge after 26 DIM. It is noteworthy that different thresholds between 5 and $7.5 \mathrm{~cm}$ for cervical diameter have been discussed as being predictive for subsequent reproductive performance (Oltenacu et al., 1983; LeBlanc et al., 2002a; Dubuc et al., 2010). The greatest difference in cervical diameter between healthy cows and cows with abnormal discharge was only 10 $\mathrm{mm}$ at $3 \mathrm{wk}$ postpartum (Oltenacu et al., 1983). A more recent study also demonstrated a relationship between fertility and cervical diameter determined by ultrasound, but not between transrectal palpation findings and reproductive performance (López-Helguera et al., 2012). Our data demonstrating high variability of estimates of cervical diameters obtained by transrectal palpation might help explain these conflicting results.

In our study, the overall prevalence of cows with a cervical diameter of $>7.5 \mathrm{~cm}$ was $13.1 \%(\mathrm{n}=8)$. Not a single cow was diagnosed with a cervical diameter of $>7.5 \mathrm{~cm}$ between 21 and 27 DIM. In an older study (Oltenacu et al., 1983), a prevalence of $26 \%$ was reported when examining cows between 12 and 26 DIM with a cutpoint of $>5 \mathrm{~cm}$ for cows in first lactation and $\geq 6$ $\mathrm{cm}$ for cows in second or greater lactation. More recent studies described a prevalence of cervical diameter $>7.5$ $\mathrm{cm}$ of $6.6 \%$ (LeBlanc et al., 2002a) and $4.4 \%$ (Dubuc et al., 2010), respectively. These prevalence rates were based on animals examined between 20 and 33 DIM (LeBlanc et al., 2002a) and $35 \pm 3$ DIM (Dubuc et al., 2010), whereas we examined cows between 2 and 5 DIM and between 21 and 27 DIM in the present study. We included the early postpartum period to increase the variation of cervical diameters because the overall objective was to study the accuracy and repeatability of transrectal assessment of the cervical diameter, not to determine the prevalence of clinical endometritis for a certain interval postpartum. Cervical diameter of cows 

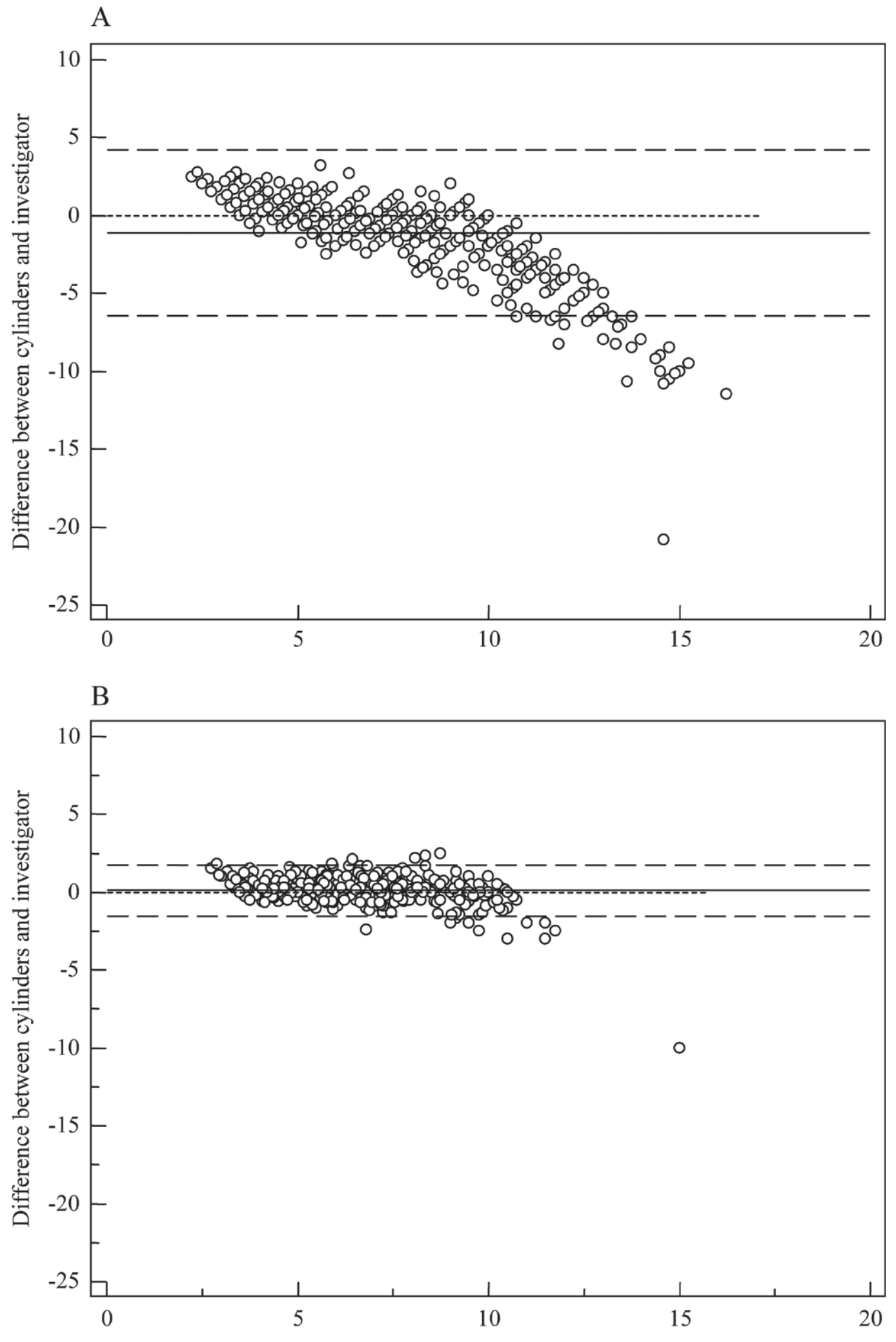

Average of cylinders and investigator

Figure 1. Bland-Altman plots comparing the actual diameters of cylinders and the diameters assessed by the investigators by palpation (in vitro). Data are shown for group A for replicates 1 to 5 (A: mean $=-1.11,95 \%$ CI: -6.4 to 4.2 ) and replicates 6 to 10 (B: mean $=0.11,95 \%$ CI: -1.5 to 1.7 ). The horizontal lines indicate $95 \%$ CI (dashed lines) and mean difference (solid line). 

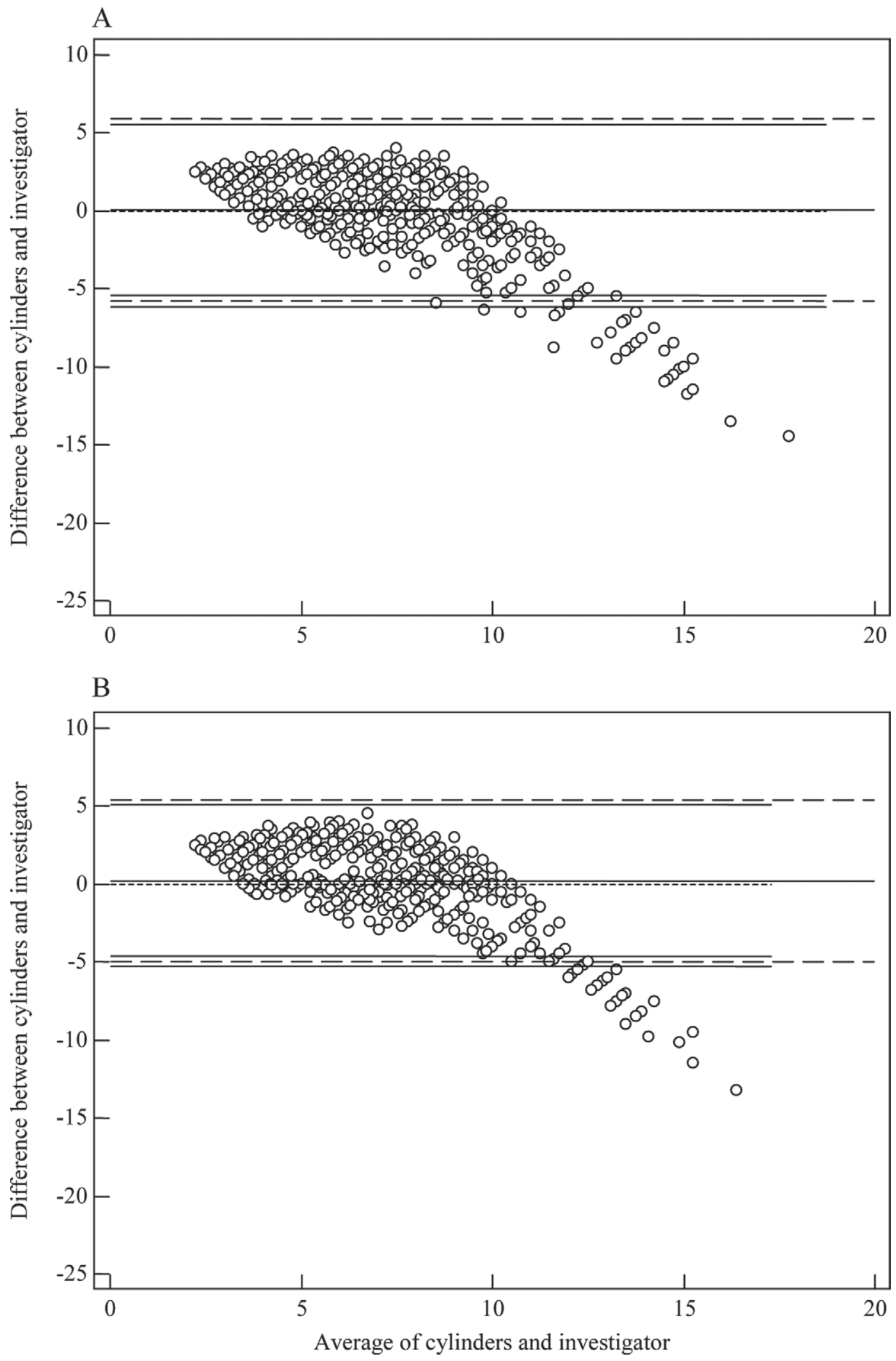

Figure 2. Bland-Altman plots comparing the actual diameters of cylinders and the diameters assessed by the investigators by palpation (in vitro). Data are shown for group B for replicates 1 to 5 (A: mean difference $=0.07,95 \%$ CI: -5.8 to 5.9 ) and replicates 6 to 10 (B: mean difference $=0.22,95 \%$ CI: -5.0 to 5.4). The horizontal lines indicate $95 \%$ CI (dashed lines) and mean difference (solid line). 
between 21 and 27 DIM differed only slightly $(4.3 \pm 0.6$ $\mathrm{cm}$ ), with a maximum of $6.7 \mathrm{~cm}$. These data are in line with a study examining 53 cows 3 times postpartum and reporting a cervical diameter of $3.1 \pm 0.3$ (CI: 2.5 - 4.0) at 22 to $28 \mathrm{~d}$ postpartum (López-Helguera et al., 2012). In addition, the authors of that study did not report any cows with a cervical diameter $>7.5 \mathrm{~cm}$.

As the cervix starts to regain its firm structure and the cervical diameter shrinks to $5.3 \mathrm{~cm}( \pm 1.0)$ at $48 \mathrm{~h}$ postpartum (van Engelen et al., 2007), we assumed that examination of the cervix by palpation and ultrasound would be possible at this early stage of involution. Thus, we decided to include cows as early as $48 \mathrm{~h}$ postpartum as well. It is obvious that an early examination will lead to false-positive cases, considering the definition of endometritis specified by LeBlanc et al. (2002a) for the fourth week after calving, as physiological involution of a healthy uterus requires at least 3 wk (Morrow et al., 1969; LeBlanc et al., 2002b; Gilbert et al., 2005).

The accuracy of a diagnostic test can be defined by comparing the outcome of the test with an established standard diagnosis, the gold standard (Knottnerus et al., 2002). In our study, we created references with ultrasound-generated measurement in vivo and wooden cylinders in vitro, and thus were able to calculate sensitivity and specificity. Ultrasonography is a reliable method for measuring the uterine horns and the cervix (Kasimanickam et al., 2004; Sheldon et al., 2006), but we conducted our experiments on the assumption that some variation also occurs in ultrasound-based measurements due to the position or angle of the scanner relative to the anatomical structure and the shape of the structure. Data from experiments 1 and 2 clearly demonstrate that ultrasound-based measurements can be used as a reliable reference standard. Correlation within one investigator was $0.97(P=0.01, \mathrm{n}=61)$. Between 2 investigators, both correlation $(0.99, P=$ $0.01, \mathrm{n}=61$ ) and repeatability (mean: $0.01 \mathrm{~cm}, 95 \% \mathrm{CI}$ : -0.48 to $0.51 \mathrm{~cm}$ ) were excellent. Coefficient of variation between independent measurements was $3.4 \%$. It is obvious that the cervix of a cow is not perfectly round. To minimize bias, the ultrasound images were measured vertically and horizontally, and the mean was calculated for further analysis.

The overall sensitivity and specificity for all 3 investigators, considering ultrasound in vivo as the reference standard, were 37.5 and $96.2 \%$. Sensitivity of the in vivo trial was not satisfactory. In particular, cervical diameters of $\geq 6 \mathrm{~cm}$ confused the investigators and led to false-positive findings. This observation was confirmed in the in vitro trial, where the variability of the manual assessment increased with increasing diameter (diameter of $10.5 \mathrm{~cm}$ : mean $\pm \mathrm{SD}=13.2 \pm 4.0 \mathrm{~cm}$; Figure 2a).
Evidence for the calculated sensitivity and specificity (respectively 28.6, 42.9, and $42.9 \%$ and 100, 96.2, and $92.6 \%$ for Inv 1, 2, and 3) in vivo is limited because of the small number of cows $(n=8)$ with a large cervix and possible confounding by a different texture of the tissue early postpartum. Furthermore, transrectal palpation of the uterus to assess its size lacks diagnostic accuracy (Sheldon et al., 2006) and predictive value in respect to fertility (López-Helguera et al., 2012). Thus, we calculated sensitivity and specificity in vitro for comparison with previous studies. The sensitivity was not satisfactory, but the results of this experiment show that the ability of the investigators to manually assess different diameters was reasonable and could be improved through training, as demonstrated for group A (before training: $73.2 \%$, after training: $85.9 \%$ ).

Dubuc et al. (2010) calculated a sensitivity of 4.9 and $50.8 \%(35 \pm 3 \mathrm{DIM})$ considering thresholds of a cervical diameter $>7.5 \mathrm{~cm}$ and $>5.0 \mathrm{~cm}$, respectively, using predicted pregnancy status $120 \mathrm{~d}$ after parturition, as reference. Calculating sensitivity based on confirmed pregnancy status as a reference has to be seen as critical. The low sensitivity can be explained by the considerable time lag between diagnosis and pregnancy confirmation and by the multitude of factors that may influence pregnancy status (Kasimanickam et al., 2004; Barlund et al., 2008).

Our data of the estimates of cervical diameters obtained through transrectal palpation conducted independently by 3 investigators did not show a significant difference $(P=0.12)$ but did show low correlation values $(\mathrm{r}=0.79,0.52$, and 0.49 ; all $P<0.001)$ and high variation $(\mathrm{CV}=19.4,33.3$, and $33.8 \%)$. Plotting the differences between ultrasound measurements and estimates obtained manually against the mean of the 2 values showed that disagreements between the methods were evenly distributed across the range. Ultrasoundbased measurements were, on average, $0.60 \mathrm{~cm}$ greater than estimates obtained by transrectal palpation. The 95\% CI (lower and upper limits of agreement) for the point estimates of the mean difference were -2.4 and $3.6 \mathrm{~cm}$. By using the Bland and Altman (1986) method, approximately $95 \%$ of data points were within the lower and upper limits of agreement.

Repeatability results in vivo may have suffered from limitations due to the nature of a field trial conducted on a commercial dairy farm. To reduce bias and ensure identical conditions for the 3 investigators, we minimized the time lag between investigators to less than 1 min. The number of investigators in our in vivo experiment was limited to 3 to minimize strain on the animals and avoid the risk of rectal lesions. Furthermore, it has been speculated previously that transrectal stimulation causes uterine tone to increase contractions (McDougall 
et al., 2007; Pleticha et al., 2009), which might affect cervical diameter. These limitations were eliminated by the design of the in vitro trial. Besides the availability of an absolute reference standard, a greater number of investigators could be used and greater variation of different diameters could be examined. Furthermore, the effect of training could be studied. For the in vitro trial, diameters from 3.5 to $10.5 \mathrm{~cm}$ in $0.3-\mathrm{cm}$ increments were used. Wood was chosen as the material for the cylinders to ensure that the diameter could not vary due to compression or manipulation during the trial following several palpations. This is the first report related to dairy cattle to demonstrate that the human ability to manually assess different diameters by palpation can be trained (Figures 1 and 2). Correlation and variation clearly improved after training. Further research is warranted to determine how this effect can be implemented in in vivo situations.

\section{CONCLUSIONS}

This study showed that the repeatability of an estimate of the cervical diameter obtained through transrectal palpation was moderate. On average, the results from palpation were $0.6 \mathrm{~cm}$ lower than the measurements generated by ultrasound. Variation increased with increasing diameters and the correlation between the investigators was low. Cows with a cervical diameter of $>6.0 \pm 0.2 \mathrm{~cm}$ were falsely diagnosed as having a cervical diameter $>7.5 \mathrm{~cm}$ (a false-positive result). The ability to assess different diameters by palpation can be improved significantly through training. Overall, our data provide clear evidence that manual assessment of diameters by palpation remains a challenge. This finding should be considered when categorizing cows into healthy or metritic groups based on a threshold for cervical diameters.

\section{ACKNOWLEDGMENTS}

We thank the manager and staff members of the farm and the participants of the in vivo and in vitro experiments for their support. Furthermore, we thank Julia Plöntzke, Onno Burfeind, and Vishal Suthar (Clinic of Animal Reproduction, Faculty of Veterinary Medicine, Freie Universität Berlin, Germany) for invaluable proofreading and advice on the statistical analyses.

\section{REFERENCES}

Barlund, C. S., T. D. Carruthers, C. L. Waldner, and C. W. Palmer. 2008. A comparison of diagnostic techniques for postpartum endometritis in dairy cattle. Theriogenology 69:714-723.
Bekana, M., P. Jonsson, and H. Kindahl. 1996. Intrauterine bacterial findings and hormonal profiles in post-partum cows with normal puerperium. Acta Vet. Scand. 37:251-263.

Bekana, M., P. Jonsson, and H. Kindahl. 1997. Bacterial isolates associated with retained fetal membranes and subsequent ovarian activity in cattle. Vet. Rec. 140:232-234.

Bland, J. M., and D. G. Altman. 1986. Statistical methods for assessing agreement between two methods of clinical measurement. Lancet 8476:307-310.

Dohmen, M. J., K. Joop, A. Sturk, P. E. Bols, and J. A. Lohuis. 2000. Relationship between intra-uterine bacterial contamination, endotoxin levels and the development of endometritis in postpartum cows with dystocia or retained placenta. Theriogenology 54:1019-1032.

Dubuc, J., T. F. Duffield, K. E. Leslie, J. S. Walton, and S. J. LeBlanc. 2010. Definitions and diagnosis of postpartum endometritis in dairy cows. J. Dairy Sci. 93:5225-5233.

Gilbert, R. O., S. T. Shin, C. L. Guard, H. N. Erb, and M. Frajblat. 2005. Prevalence of endometritis and its effects on reproductive performance of dairy cows. Theriogenology 64:1879-1888.

Kasimanickam, R., T. F. Duffield, R. A. Foster, C. J. Gartley, K. E. Leslie, J. S. Walton, and W. H. Johnson. 2004. Endometrial cytology and ultrasonography for the detection of subclinical endometritis in postpartum dairy cows. Theriogenology 62:9-23.

Kelton, D. F., K. E. Leslie, W. G. Etherington, B. N. Bonnett, and J. S. Walton. 1991. Accuracy of rectal palpation and of a rapid milk progesterone enzyme-immunoassay for determining the presence of a functional corpus luteum in subestrous dairy cows. Can. Vet. J. $32: 286-291$.

Knottnerus, J. A., C. van Weel, and J. W. Muris. 2002. Evaluation of diagnostic procedures. BMJ 324:477-480.

LeBlanc, S. J., T. F. Duffield, K. E. Leslie, K. G. Bateman, G. P. Keefe, J. S. Walton, and W. H. Johnson. 2002a. Defining and diagnosing postpartum clinical endometritis and its impact on reproductive performance in dairy cows. J. Dairy Sci. 85:2223-2236.

LeBlanc, S. J. T. F. Duffield, K. E. Leslie, K. G. Bateman, G. P. Keefe, J. S. Walton, and W. H. Johnson. 2002b. The effect of treatment of clinical endometritis on reproductive performance in dairy cows. J. Dairy Sci. 85:2237-2249.

López-Helguera, I., F. López-Gatius, and I. Garcia-Ispierto. 2012. The influence of genital tract status in postpartum period on the subsequent reproductive performance in high producing dairy cows. Theriogenology 77:1334-1342.

McDougall, S., R. Macaulay, and C. Compton. 2007. Association between endometritis diagnosis using a novel intravaginal device and reproductive performance in dairy cattle. Anim. Reprod. Sci. 99:9-23.

Morrow, D. A., S. J. Roberts, and K. McEntee. 1969. Postpartum ovarian activity and involution of the uterus and cervix in dairy cattle. II. Involution of uterus and cervix. Cornell Vet. 59:190-198.

Oltenacu, P. A., J. H. Britt, R. K. Braun, and R. W. Mellenberger. 1983. Relationships among type of parturition, type of discharge from genital tract, involution of cervix, and subsequent reproductive performance in Holstein cows. J. Dairy Sci. 66:612-619.

Pleticha, S., M. Drillich, and W. Heuwieser. 2009. Evaluation of the Metricheck device and the gloved hand for the diagnosis of clinical endometritis in dairy cows. J. Dairy Sci. 92:5429-5435.

Runciman, D. J., G. A. Anderson, J. Malmo, and G. M. Davis. 2008. Use of postpartum vaginoscopic (visual vaginal) examination of dairy cows for the diagnosis of endometritis and the association of endometritis with reduced reproductive performance. Aust. Vet. J. $86: 205-213$.

Sheldon, I. M., G. S. Lewis, S. LeBlanc, and R. O. Gilbert. 2006. Defining postpartum uterine disease in cattle. Theriogenology 65:1516-1530.

van Engelen, E., M. A. Taverne, M. E. Everts, G. C. van der Weijden, A. Doornenbal, and V. N. Breeveld Dwarkasing. 2007. Cervical diameter in relation to uterine and cervical EMG activity in early postpartum dairy cows with retained placentas after PGF2alpha induced calving. Theriogenology 68:213-222. 